\title{
Test anxiety: perceptions of American community college nursing students
}

\author{
Dongfang Liu ${ }^{1 *}$ and Bo Xu
}

\author{
${ }^{*}$ Correspondence: \\ 155085293@qq.com \\ ${ }^{1}$ College of Education, \\ Southwest University, \\ Chongqing 400030, China \\ Full list of author information \\ is available at the end of the \\ article
}

\begin{abstract}
Background: Nowadays, there are common phenomena among college nursing students who reported increasingly test anxiety. The purpose of this phenomenological study was to increase understanding of American community college nursing students and their experiences using anextended time and other form of supportive accommodation to address test anxiety.

Methods: This study utilized focus group interview and carefully selected eight participants to join this research. The authors completed coding, categorizing, and identification of themes based on Moustakes' (1994, in Phenomenological research methods. Sage, Thousand Oaks) approach to data analysis. A transcription of the focus group recording was read to inform a general impression of the experiences of our participants. A final list of significant statements was developed, and from this list the authors grouped them into larger units of information and from these units, identified common themes (Creswell 2013 in Qualitative inquiry and research design: choosing among five approaches. Sage, Thousand Oaks).

Results: Implementation of, and data analysis from, an eight-member focus group interview revealed six themes: (a) students' feelings of being anxious and overwhelmed, (b) the impact of nursing school stress, (c) the perceived benefits of using test accommodations, (d) environmental influences, (e) challenges and supportive structures for securing accommodations, and (f) metaperception of stigmatization.

Conclusions: In this study, students reported a benefit from using extended time for testing and noted the importance of the testing environment as an essential feature of the accommodation. Challenges faced by students included the ordeal of getting a diagnosis and potential for stigmatization. Participants indicated teachers provided essential support during this process. Study results suggest extended time accommodation provides an added level of fairness in the process of learning evaluation.
\end{abstract}

Keywords: Nursing students, Accommodations, Extended time, Test anxiety

\section{Background}

As policy makers focus on the importance of higher education, college enrollment stands at an all-time high (National Center for Education Statistics 2015). This increased enrollment results in a rise in the number of students with disabilities. In higher education, freshman with disabilities increased fourfold between 1978 and 1994, changing from 2.6\% of the freshman class to 9.2\% (Henderson, 1995, as cited in Kurth and Mellard 2006). Students with disabilities maintain the legal right to request and use 
accommodations to provide equitable opportunities for success in higher education and one important form of accommodations is extended test time. Students request extended testing time more than any other accommodation (Bolt et al. 2011; Kurth and Mellard 2006). In nursing schools, where competition and high-stakes testing exist in most programs, the stressful nature of participating in a nursing program may increase the number of students citing an anxiety disorder as the basis for applying for extendedtime accommodations to counterbalance of the test anxiety. The research question that guides this study is, "What are the experiences of nursing students using extended time as an accommodation for test anxiety?" This question holds a unique distinction in that it challenges the validity of a common intervention for test anxiety and focuses on a student population that experiences more anxiety than others due to the differences of accommodations during tests. Additionally, while quantitative research regarding extended-time accommodations abounds (Bolt et al. 2011; Kurth and Mellard 2006; Lewandowski et al. 2014), a dearth of qualitative evidence exists.

Quantitative research forms the basis of the majority of the literature related to testing accommodations and its focus lies in the effects of interventions rather than students' perceptions. Currently, no qualitative studies found in a focused literature search specifically address the nursing student population. The purpose of this phenomenological study centers on understanding of the nursing students' experiences of utilizing testing accommodations to manage test anxiety. Eight nursing students from a mid-western community college participated in a 60 -min focus group interview to examine their perception of using accommodations to abate test anxiety and how they believe their peers view the practice. The research findings provide information regarding nursing students' perceptions of the role of accommodations in addressing test anxiety and their metaperception of how others view their use of test accommodations to encounter the pressure during tests. The results can be useful to faculty members and disability services staff members to better support nursing students and create an impartial environment for all students.

\section{Literature review}

\section{Test anxiety and accommodations}

Situations perceived as threatening can cause individuals to experience anxiety with the potential for less effective functioning (Edelman and Ficorelli 2005). Pioneer researchers in the area of test anxiety define it as a specific, focused, fear pattern in response to a situation involving evaluation of a student's performance (Serok 1991). Test anxiety may manifest itself in physiologic and behavioral responses that accompany these fear patterns (Ergene 2003; Sapp 1996). In some cases, individuals with high levels of test anxiety experience severe performance declines (Cassady and Johnson 2001).

Test anxiety results in problems for many people including those enrolled in higher education institutions (Driscoll et al. 2009). Previous research links test anxiety to poor academic performance, a decreased attainment of degrees, and limited career options (Enright et al. 2000; Ergene 2003; Kennedy and Doepke 1999; Mealey and Host 1992). Cognitive test anxiety can account for a seven to eight percent drop in test grades (Cassady and Johnson 2001). 
Literature regarding students' perceptions of accommodations to address test anxiety consistently revealed both students with disabilities and nondisabled students believe extended time for testing provides a benefit (Elliott and Marquart 2004; Lewandowski et al. 2014; Lovett and Leja 2013). Elliott and Marquart (2004) studied the perception of extended time and reported that $78 \%$ of students with disabilities and $87 \%$ of nondisabled students felt more relaxed when using extended time. Lovett and Leja (2013) used pre- and post-questionnaires and found that only those students who received accommodations for test anxiety experienced a drop in anxiety, indicating that the use of test accommodations presents a benefit specific to those suffering from anxiety. These students also indicated gains in self-efficacy based on post questionnaire responses. A study by Lewandowski et al. (2014) regarding college students' preferences for test accommodations indicated not only a consistent positive perception about the use of extended time, but also an added benefit on high-stakes exams compared to classroom tests.

Although the majority of studies indicate a positive perception of testing accommodations, some research asserts that variability exists in how students perceive the use of accommodations (Bolt et al. 2011; Kurth and Mellard 2006; Rickey 2005). One study found the approach used by school administrators to address accommodations influences student perceptions of test accommodations (Rickey 2005). Rickey (2005) studied three different middle schools, interviewing a variety of stakeholders. In schools where administrators frequently justified the use of accommodations, students reported positive perceptions of accommodations. When administrators showed more ambivalence, student opinion followed (Rickey 2005).

Research demonstrating a negative effect of testing accommodations also exists. Kurth and Mellard's (2006) extensive study of postsecondary students found some respondents felt a lack of belonging when they used test accommodations. Additional negative consequences surfaced in a study conducted by Bolt et al. (2011). When researching the differences between high school and college students' perceptions of accommodations, these researchers found that some faculty members reported negative attitudes about accommodating students with mild disabilities. Additionally, students would choose to relinquish their accommodations based on feelings of being stigmatized, and a minority (7.4\%) indicated their "own embarrassment kept them from using accommodations" (Bolt et al. 2011, p. 171). Research from the National Center on Educational Outcomes also suggests the presence of controversy surrounding the fairness of test accommodations, which students should have access, and how those decisions are made. Lastly, Lewandowski et al. (2014) noted that students may be willing to feign symptoms of disabilities or exaggerate those symptoms in order to be granted approval to use testing accommodations.

\section{Anxiety and accommodations for nursing students}

Nursing students experience test anxiety at a higher rate than other college students due to the demanding nature of the nursing curricula, the expectation to balance employment and family responsibilities with coursework, and the requisite study time needed for success (Beggs et al. 2011). According to Driscoll et al. (2009), when compared to high school students and the general public, nursing students experience more than double the rate of moderately high to high test anxiety. Cognitive test anxiety can account for a seven to eight percent drop in test grades (Cassady and Johnson 2001). The anxiety 
experienced during nursing examinations affects students physically, emotionally, and cognitively, and can prove detrimental to their success (Shapiro 2014). Because as many as $30 \%$ of nursing students report test anxiety, interventions to assist these students bear investigation (Driscoll et al. 2009).

Extended testing time stands as the most popular and widely used accommodation for nursing students who report anxiety related to testing. The literature reveals alternative strategies aimed at reducing or relieving test anxiety among nursing students including aromatherapy, relaxation training, hypnotherapy, and music with a very slow pace (Shapiro 2014). Conversely, one study suggested that some students experience no benefit from extended testing time, but this study excluded students with anxiety and included subjects with diverse college majors (Lee et al. 2010).

All students in higher education bear the responsibility to self-disclose any disabilities and to request appropriate accommodations. Kafle (2015) conducted a study of nursing students who were eligible to receive accommodations and their perceptions of the effects of self-disclosure of a learning disability. The findings indicated that the students may be reluctant to disclose their disability due to fear of stigmatization. Despite these fears, the perceived benefits of accommodations, including extended time, resulted in the students' disclosure of a learning disability (Kafle 2015).

The correct utilization and fairness of extended time accommodations caused much debate among educators more than a decade ago and continues today. In 2004, Lerner and Lichtenburg charged that some students erroneously seek a diagnosis of a learning disability in order to receive an unfair advantage in testing (Lovett 2011). Others argued that extended testing time accommodations may be awarded too liberally, resulting in lower validity of exam scores (Lovett 2011). A dearth of literature exists, however, regarding the perceptions and metaperceptions of nursing students who use extended testing time accommodations for anxiety.

\section{Methods}

\section{Research design}

An interpretivist perspective guides this research study. The interpretivist worldview suggests that meaning is made through human interaction and that the social world is "produced through meaningful interpretations" (Pascale, 2011, p. 22 as cited in Jones et al. 2014). This study followed a phenomenological approach to facilitate understanding of the experiences of nursing students. As the name implies, phenomenology is the "exploration of a phenomenon" (Creswell 2013, p. 78) with several participants who all have a common experience. The authors used a basic qualitative focus group design. A focus group consists of several individuals with some common characteristics who engage in an interview focused on a specific subject. Focus groups are less threatening to many research participants, and provide an environment conducive to the discussion of perceptions, ideas, opinions, and thoughts (Krueger and Casey 2000). This research method promotes a rich resource for the exploration of experiences, emotions, and feelings. Interactions that occur during focus groups among the participants can yield important data (Morgan 1988), can create the possibility for more spontaneous responses (Butler 1996), and can provide a setting where the participants openly discuss personal problems and provide possible solutions (Duggleby 2005). 
With Institutional Review Board approval, the participants in this study were eight nursing students enrolled in a nursing program at a mid-sized community college in the mid-western United States. The authors used criterion sampling to select participants. The participants self-identified as having met the criteria, which included, participation in the nursing program, having a diagnosis of test anxiety, and using an extended-time testing accommodation. Participants were contacted via email with a description of the study and invited to participate in the study. The participants' demographics included variations in gender, race, nationality, preferred language, and sexual orientation. Participants agreed to sign consent forms and participated voluntarily in the study.

\section{Data collection}

For purposes of the study, students attended a focus group and were asked semi-structured questions. A focus group interview with all eight participants was completed on the college campus. The authors joined the group using $\mathrm{WebEx}^{\circledR}$. This video conferencing program was used to facilitate and record the session. During the session, the authors asked seven semi-structured questions (Appendix) and prompts were used to expand the students' explanations of each question. This type of interview allowed the participants the flexibility to share their feelings and perceptions openly. Participants were encouraged to elaborate on their answers and the authors allowed a natural flow of conversation to direct the discussion and explore the students' thoughts, feelings, and experiences in greater depth (Patton 2002). Participants were first provided with a set of pre-selected photographs depicting a variety of themes. Participants selected the photograph that best illustrated their feelings when taking tests and shared their interpretation of the image. The authors facilitated the sharing of ideas by all participants through the use of follow-up questions and personal appeals. The opening questions introduced the topic and initiated group discussion by focusing on the participants' individual experiences with extended time for test accommodations. Questions then centered on participants' own perceptions of how others perceived them (metaperception) as an individual with test taking accommodations. Concluding questions focused on the meaning the participants placed on their experiences and how these experiences may have changed their feeling towards testing accommodation resources available for nursing students requiring these services. Probes were used throughout the discussion to elicit further information and to ensure that the participants had discussed everything they felt relevant before moving on to the next question. Participants were offered the opportunity to ask questions, add any other information they found interesting, and then they were thanked for their time and effort. Finally, participants were asked to complete a short survey on their personal demographics.

\section{Analysis of data}

The authors completed coding, categorizing, and identification of themes based on Moustakes' (1994) approach to data analysis. A transcription of the focus group recording was read to inform a general impression of the experiences of our participants and identify participant statements that were significant to the experience of using test accommodations. A final list of significant statements was developed, and from this list the authors grouped them into larger units of information and from these units, identified common themes (Creswell 2013). 
The authors identified frequently repeated and consensus statements as those which should be considered as most significant. Based on these significant statements and the themes, the authors wrote an exhaustive description of 'what' the nursing student participants experienced related to test accommodations. Representative quotes were identified to support the narrative. The authors also wrote an exhaustive description of 'how' the nursing student participants experienced test accommodations. The authors addressed questions such as, "How does the high-stress environment of a nursing program affect their experience?" and "How does the perception of faculty, other students, and college staff affect their experience?" Once again, representative quotes were identified to support the description. A final narrative was written to describe the essence of the experience to complete the data analysis through writing. This narrative is based on the composite of the first two narratives and therefore includes the 'what' and the 'how' of the students' experiences. The process outlined by Moustakes (1994), which includes examination of the data for themes, using writing as a means to analyze, and including researcher reflection, "yields an explicit structure of the meaning of the lived experience" (Creswell 2013, p. 195).

\section{Findings}

In this study, eight nursing students were interviewed with six female participants and two male participants. Five students were in their sophomore year and three of them were freshmen in College. The participants were selected for the study, because they had a diagnosis of test anxiety and utilized an extended-time testing accommodation. In reviewing the data from the focus group interview and the photo elicitation exercise, the authors sought to better understand nursing students' experiences of test accommodations within their school situation and their perception of how others view the practice. Six themes emerged as nursing students described their experiences and feelings toward test accommodations: (a) students' feelings of being anxious and overwhelmed, (b) the impact of nursing school stress, (c) the perceived benefits of using test accommodations, (d) environmental influences, (e) challenges and supportive structures for securing accommodations, and (f) metaperception of stigmatization.

\section{Anxious and overwhelmed feelings}

Community college nursing students who use the extended time testing accommodation described experiences of feeling anxious, overwhelmed and stressed. The feeling of anxiousness is defined as feeling afraid or nervous especially about what may happen, feeling anxiety, and wanting or eager to do or have something very much especially because of fear or nervousness (Merriam-Webster 2015). Taylor reported similar descriptions of feelings during the photo elicitation segment of the focus group interview stating, "I picked the crowded school thing because I get very overwhelmed and anxious in compared to everyone else. ... I feel very overwhelmed and crowded, competitive, anxious there's just a lot going on right before a test in my brain." Similarly, Sarah described her test anxiety and stress as "people with anxiety go, 'oh my gosh, why did I go into nursing school? I'm the dumbest person here', like you have...(uses hand to make circular gesture around head like a recording playing)... and you just can't move past it (most participants voicing agreement). Like, I can blow an entire test because I can't move on past the first answer." 
Community college nursing students report varying levels of anxiety related to many of the activities associated with nursing tests including the testing process, use of the testing center, and navigating the requirements to obtain testing accommodations. Specifically regarding testing, students reported levels of anxiety they perceived as higher than that of their peers. Taylor said, "I get very overwhelmed and anxious in compared to everyone else." Regarding seeing the first low score on a nursing exam, Jacob said, "So a panic attack ensues that there's gonna be a plane that falls out of the sky and it's definitely gonna be on top of my car." A consistent theme of anxiety, worry, and nervousness pervades all aspects of the conversations related to testing in nursing school.

\section{Nursing school stress}

When students become overwhelmed during test taking their fear of failing can overtake them, especially after having faced stiff competition to gain entrance to nursing school. Sarah described her experience saying, “Like, we don't wanna be the ones that failed. Because you're like, I feel so tense here. I'm not gonna pass nursing school. Then what else am I gonna do because I don't want to redo this...because it's way too much." Jacob described the overall environment: "When you're in nursing school, I think we can all agree, it's a hostile environment anyways. It's very rigorous, it's very tough. You have something to do every day." When Jacob described the photograph he selected in the photo elicitation activity, he emphasized the stress of attending nursing school when describing his image of a train (see Fig. 1), "I chose the train covered in people because, let's be honest, everybody's on the same train to either passing or failing... people are going to be hurt in this entire situation is more likely because of how much stress is surround and just hanging on by a thread and that would be me." The competitive entrance requirements associated with nursing school contributes to the nursing students' experience of test anxiety and the use of test accommodations.

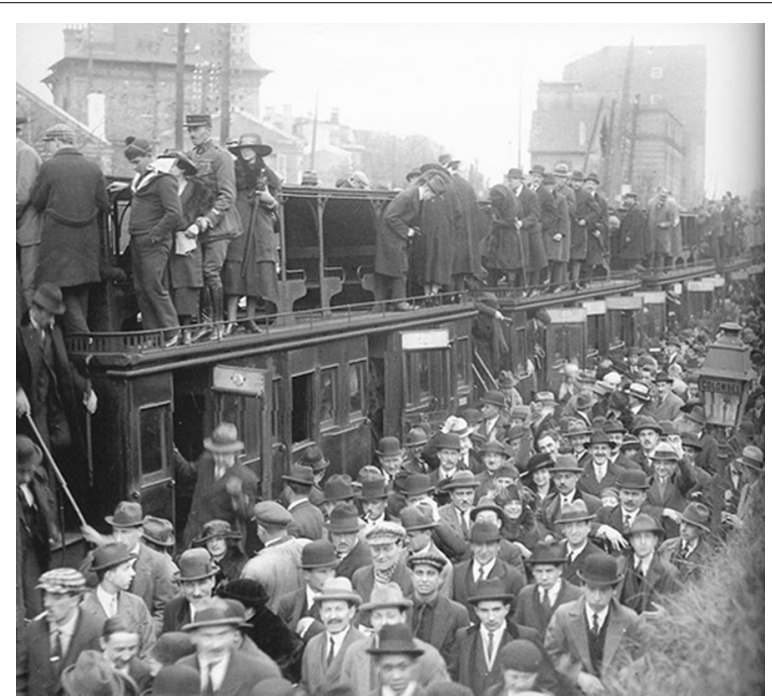

Fig. 1 Demonstration of anxiety of elicitation exercise 


\section{Perception of benefit}

All of the student comments described test accommodations in a positive manner. Students shared highly emotive descriptions of the benefits, such as Casey's comment, "It really is life-changing." All of the community college nursing students found the extended time accommodation beneficial, and indicated it aided their test taking capacities. Jacob stated "Having that extra time, having that extra cushion, is very.... It takes out just one of those stressors that testing gives you." Casey agreed with Jacob saying, "The extra time was game changing for me. That's what I needed. That's the whole reason why I was in there [testing center] because I would find myself stressing about the time and breaking concentration from the test to look at the clock to make sure that I had enough time." All of the participant students who use the extended time test accommodation shared positive experiences and thoughts about the beneficial impact of the accommodation on their test outcomes.

Additionally, all student participants expressed support for providing extended time for all students. The authors shared the concept of Universal Design for Assessment (UDA) with the students, and received primarily positive feedback from the focus group. Jordan echoed the group's sentiments saying, "You know, if it was just given to everybody, you wouldn't have to go through, like you have to go to the doctor and pay for the doctor's visit. And then we talked about how it is an issue for international students...It should be an option for everybody." Fellow students Emerson and Taylor agreed, "I think it's beneficial for everyone. Like, even if they don't use it, just like that extra cushion is nice to have." "It's good for everyone, as long as nobody abuses it, and uses it wisely, I don't see a downfall." Two of the students shared some concern about making extended time available to everyone. Jacob stated, "I think it should be circumstantial," and Amari suggested, "I do think it depends on the person." UDA carries significant implications on testing within secondary and postsecondary environments. The feedback from this focus group, however, suggests that students would be open to the idea of providing extended time to all students, and many would welcome the opportunity to have the option of extended time without having to go through the challenging application process. These findings confirm those cited in previous research on accommodations (Elliott and Marquart 2004; Lewandowski et al. 2014; Lovett and Leja 2013).

\section{Environmental influences}

A frequent theme that emerged from the focus group centered on the influence of the environment and how it contributed to community college nursing students' experiences of test anxiety. When surrounded by a room full of other nursing students, already anxious students feel their anxiety levels increase. Factors such as the physical environment of the classroom, the ticking clock, or the sound of other students fumbling with papers or breathing loudly combine to cause feelings of being overwhelmed and the loss of mental function, essentially causing students to forget everything previously studied. Jacob, noted, "You get to a question and immediately question every bit of the studying you've done." The nursing students perceive the environment as a distraction and a trigger for text anxiety. Sarah agreed with Jacob. Sarah stated "I could do the test in the same time as everybody I just can't... for some reason I can't be in the same room with everybody. I just don't...I don't thrive well." Jacob shared his enthusiasm for a separate 
environment, "You don't really understand how much of a blessing it is." The environment emerged as a common theme among many of the students.

Students found a testing center or library environment to be much more conducive to test taking and indicated these environments minimize anxiety and feelings of being overwhelmed. The library and testing center provide welcoming environments for the nursing students. In these settings, students have more privacy and are able to get up, walk around, and use the restroom if necessary. They also have the opportunity to relax and take a break if necessary. Taylor shared her feelings, "This semester, they're letting us go to the library so we can have that accommodation room and the bathroom and be able to like, take a breath..." Additionally, the students shared examples of how faculty members provided systems for privacy in the testing area. Students described cardboard dividers that were used to give them privacy during testing. Jacob described the partitions, "What they give us is you have the option to use, it's like a barrier, a cardboard barrier thing." And Taylor shared appreciation for the partitions, "It's nice to be able to have your own bubble, your own space, quiet, it's nice to focus." Clearly, the ability to focus, and not be distracted by environmental disturbances, supports how nursing students experience test taking, and more specifically, how they experience testing accommodations.

\section{Securing accommodations}

Participants made many comments related to how nursing students secure test accommodations. The authors heard about the challenges, the supportive structures, as well as a variety of reasons for requesting extended time. The data from this study suggests that testing accommodations provide a positive influence on learning and test taking, however, the nursing students reported challenges and stressors related to receiving approval. One of the challenges reported was the requirement to receive a diagnosis of anxiety from a qualified professional. Taylor shared, "You hear about all these people going to the doctor just to get on meds and abusing the thing, so you kind of think they're gonna go like, 'That chick's crazy." Emerson shared similar concerns saying, "I was worried that my doctor was going to think that I was faking it-like my anxiety wasn't real and he was just going to tell me to get over it." These students expressed concern about the process and whether or not they would receive the needed diagnosis. Similarly, students worried about the additional cost incurred by the required professional evaluation requirement. The international students in particular cited inadequate healthcare coverage and therefore, paid more for the evaluation. Emerson described the concern, "We already pay so much to be at this college and...I'm not saying...well, we pay extra that other students don't and just to have that thing, it kind of gives more anxiety because we have to pay more money to get something."

In contrast to these challenges, many of the nursing students credited supportive nursing faculty members with assisting them through the process to receive approval for testing accommodations. Students mentioned teachers on several occasions as the impetus or the support structure. Taylor shared, "I had a teacher that I went to and spoke with him in his office and he kind of told me that I needed to look into it and so I went to my doctor...he wrote a note for the school for the student services, and when I had that, then they set up accommodations for my testing." She added, "Many of the teachers have 
this big open-door policy for everyone." Emerson also noted, "and I went to talk to my professor and he was like, 'are you sure you don't have anxiety? Have you talked to your doctor about it?' And I was like, 'Yea, I have', but, I was just really in denial' (fanning herself with her hands). And he was like, 'you really should look into it, I think it would help a lot." Students appear to appreciate the support offered by their faculty members and suggest that many students would not make the effort to secure testing accommodations without the encouragement of their teachers.

More than one benefit of testing accommodations emerged from the data. In addition to test anxiety, students reported using extended time to support second language challenges and to provide a quiet environment that naturally accompanies the extended time accommodation at this community college. ELL student Emerson shared, "For me, the extra time is mostly because, English being the second language, even though you don't want to, sometimes you have to translate back into your language- some parts of the question-and again." Related to environmental support, Jacob shared, "I don't personally use the extended time." When referring to the environment Jacob also stated, "You don't hear the doors opening and closing to the bathrooms. You don't see people walking around in front of you... you don't have somebody waving their pen around in the side of your vision. You can sit and do your test like you need to." Nursing students shared several advantages to extended time, in addition to reducing text anxiety.

\section{Metaperception of stigmatization}

People commonly believe their estimates of how they appear or seem to other people match their feelings or perceptions of themselves (i.e., their metaperceptions) (Vorauer and Miller 1997). The metaperceptions described by the participants included being judged or criticized by those nursing classmates not utilizing or requesting the extended time accommodation. One illustration of this came from Casey who shared her initial anxiety about using her accommodation when she stated,

I will say that I had a lot of anxiety about going into the testing center in second semester, the first time, because I had overheard several of our students in our class say exactly what you just stated, that it does not prepare you for the real world and there were several comments made in second semester about those 'special' people who went to the testing center. And it was hurtful in the moment, but I came to the realization that I'm here for me, that I am here for my success, Jacob's not going to do it for me (pointing to Jacob), Emerson's not going to do it for me (pointing to Emerson). Nobody at this table is going to help me to get to where I need to be and pass the N-CLEX and go to work. It's on me. And so I had to put those comments- which caused me a huge amount of anxiety about what people would think- I had to put that out of my mind and do what I needed to do to be successful in nursing school. (Agreement of other participants).

Similarly, one story shared during the interview related a friendship being ruined over another person's perceived feelings of an individual using the accommodations. Casey said she overheard, "Get over yourself" and the other person said, 'You don't understand, I really do have a lot of testing anxiety', and the other person said, 'Well, you just need to get over it and buck up.' And so it ruined the entire friendship and places were 
traded in class, and it had been a very strong friendship, then, it just didn't last because of this issue." Another student expressed her concern about what others might think of her use of the extended time accommodation for test taking. Emerson said, "And they say it's unfair, that people take extra time, but, I am not saying...but, English being my second language, how is that unfair to me? You know, I mean, you speak English, you were born here, and you say that I don't need the extra time. Well I need to put extra time into thinking to answer these questions to save your life. So how is that unfair?"

Additionally, a student stated feelings of concern about their doctor's opinion of them when requesting the assistance. Taylor shared, "You hear about all these people going to the doctor just to get on meds and abusing the thing so you kind of think they're gonna go like, "That chick's crazy." Students utilizing extended time for test taking feel concerned and expressed a heightened awareness of how they appear to others. Participants' responses were similar to research results from previous studies that indicated a sense of stigmatization and lack of belonging when students discussed the use of accommodations (Bolt et al. 2011; Kafle 2015; Kurth and Mellard 2006).

\section{Essence of the experience}

Students who use testing accommodations feel that this tool serves as an integral contributor to their nursing school success. Although several students reported not using all of the time allotted through their accommodation, all stated that its presence was helpful. Casey described the extended time accommodation as "game changing" and the primary factor that "kept me in nursing school." Amari and Kim, both of whom are ELL students, related that having time to translate questions into their native language stands as a major benefit. They also stated that their grades improved dramatically after receiving the testing accommodation. Additionally, Emerson and Amari believed strongly enough in the power of extended time that they extolled its advantages to fellow students and encouraged them to obtain accommodations.

While fear of failure looms large as a contributor to test anxiety, many other components serve as stressors. The list of stated triggers includes: (a) the time allotted for each question, (b) the presence of a large digital clock, (c) biologic needs, (d) the possibility of having too much time in which to overthink answers, (e) noise, (f) a perceived self-deficit, (g) varying difficulty levels of questions, and (h) the presence of other nursing students. Anything that does not contribute to each student's personal success is perceived as a stressor that evokes or heightens anxiety.

The extended time accommodation-whether employed or not- stands as the keystone of students' perceived stress alleviators. That keystone is supported, however, by numerous factors comprising the arch of testing success, including: (a) reduced distractions, (b) increased mobility, (c) private environment, (d) utilizing coping techniques, (e) the ability to translate between languages, and (f) extended time. Just as many variables contribute to test anxiety, the solution in turn embodies a multifactorial toolkit for coping (Fig. 2).

\section{Implications and discussion Practice and policy}

The results of this study suggest that nursing students who experience test anxiety strongly value the opportunity to use the extended time accommodation. These 


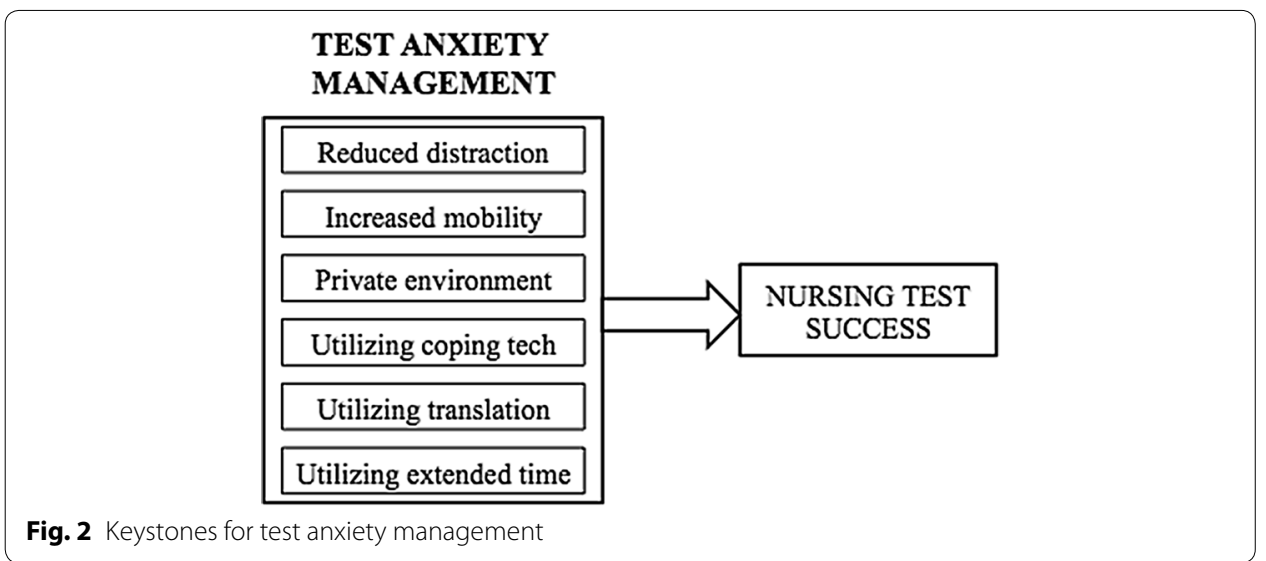

students experience anxiety at a level that impedes their performance on nursing tests, and they feel that their success as a nursing students relies heavily upon their access to the extended time accommodation. These findings lend support to the earlier research of Edelman and Ficorelli (2005) that describes the anxiety levels of nursing students as greater than those of other students. Phrases used by study participants such as "lifechanging" and "the reason I'm still in nursing school" lend credence to the idea that students at risk for failure due to test anxiety greatly benefit from the extended time accommodation. The recommendations for abating test anxiety center on the needs for extended time and environment commendations in the following paragraphs.

The most surprising insight that the authors gained while evaluating the focus group responses centers on the testing environment rather than extended time. Most participants reported not using all of their allotted time, but all of the students addressed the testing environment. Noise, feeling crowded, lack of privacy, perceived competition, a large clock, immobility, and biologic needs all added to the anxiety experienced by the study participants. At the community college where the authors conducted the focus group interview, students who receive extended time accommodations use the testing center or a large room in the school library for testing. While the students had not qualified for a reduced distraction accommodation, this aspect of the participant school's testing policy essentially granted a reduced-distraction accommodation as well as an extended time accommodation. Testing in an environment that addresses these issues provides an added measure of relief for the anxiety students experience. While a non-distraction testing area stands as the basic accommodation recommendation for students with attention deficit disorder (ADD), colleges most commonly offer only extended time as an accommodation for anxiety (Reference). Researchers recently spoke to this issue in their published guidelines for students with disabilities:

If the student is exceptionally sensitive to stimuli, such as those students with significant anxiety or ADHD, or those with obsessive-compulsive disorder, it may be necessary to allow the students to take exams in a private room. This room is still considered a reduced-distraction environment and should eliminate...distractions...(Serrantino et al. 2015, p. 59) (italics added for emphasis). Based on the relevant findings, the authors recommends that a reduced distraction accommodation in the form of a welcoming private test rooms may be a greater contributor to nursing student success than extended 
time alone. Informed by this stance, policy maker and administrators in nursing schools should consider use necessary facilities on campus to fulfill the needs for the improvement of test accommodations.

The focus group participants reported that the process required to gain an extended time accommodation adds another stressor to the already challenging nursing school experience. Fear of rejection of the anxiety claim, concern regarding stigmatization, and the financial cost of attempting to gain a documented anxiety diagnosis stand as barriers to potential success. The intervention by and encouragement from faculty members proved to be the most supportive factors in gaining accommodations according to the participants. They mentioned "an open door", probing queries, and encouragement of an attitude of self-preservation as faculty member actions that influenced their success in gaining the extended time accommodation. According to these reported ideas, the authors recommends that faculty members could actively assist the student in acquiring a qualified and professional opinion regarding the presence of test anxiety, if identifying at-risk nursing students. In addition, the authors suggests that for the students who have received the diagnosis, faculty members can reduce the stress of securing the accommodation by being receptive, nonjudgmental, and helpful in navigating the disability services at their institutions.

The metaperceptions of the participants in this study center on a reported sense of ambivalence regarding the extended time accommodation. While the students enthusiastically touted the benefits of the accommodation, they also expressed feelings of stigmatization from fellow students. While a few students felt that the accommodation should only be granted on an individual basis, most indicated that extended time allows students to accurately demonstrate their level of knowledge without offering an unfair advantage. Even students who reported using the extended time for language translation felt that their need for the extra time justified receiving the accommodation with or without the establishment of an anxiety disorder. For the ELL students, the need to translate stands as a major contributor to the heightened anxiety they experience. Based on what is presented above, the authors recommends that policy maker, administrators, and faculty members in nursing schools need to understand that the over-arching benefits of extended time for nursing students are more than just a benefit, because in some scenarios, accommodations in terms of extended time add the dimension of educational equity and fairness in the process of learning evaluation.

\section{Future research}

The limitations of this study include its small sample size of eight students, all of whom studied nursing at a mid-western community college. Further research endeavors should include focus groups that address students in associate, baccalaureate, and graduate programs from diverse locations. To further validate our claims, future research should explore the rates of success among groups of anxious students who have only the extended time accommodation without the benefit of a reduced-distraction environment. One of the strengths of this study includes the diverse demographic nature of the participants. The group included three gender identifications, four races, three countries of origin, and an age range of over 20 years. Because the English Language Learner (ELL) students spoke openly about the benefits of time to translate between languages, additional research comparing the success of ELL students who have an extended time accommodation with those 
who test within traditional time frames could lend insight into strategies to increase the graduation and licensure rates of a more diverse group of nursing students.

\section{Conclusion}

With the rise in the number of students in higher education and the ever-increasing number of students receiving accommodations, this study analyzed the experience of these students in how they acquired access to accommodations, their perceived benefits of the accommodation, their challenges and support structures, and finally, how they perceived others might view their use of accommodations. Information gleaned from this study can be used to address policy within community college nursing schools to address support structures for test taking, and acknowledgement of the stress associated with nursing school success and the corresponding fear of failure. Ongoing conversations related to providing extended time as a common practice for all students is worth noting as most participants considered the extended time accommodation as a means to provide an increased level of fairness to the process of learning and evaluation.

Authors' contributions

BX was the core member for this project and he processed the collected data. Both authors read and approved the final manuscript.

\section{Author details}

${ }^{1}$ College of Education, Southwest University, Chongqing 400030, China. ${ }^{2}$ Sichuan International Studies University, Chongqing, China.

\section{Authors information}

A former principal at the high school level where he implemented several workshops for social learning community and developed national-wide training for the supervision of certified staff. He has worked with large urban districts on building internal leadership capacity and minority leader recruitment through the Education Bureau of Chongqing for Leadership project. Dr. Liu has conducted research on educational policy implementation, standards-based assessment, school finance, international education, and low SES students'school success.

\section{Acknowledgements}

The paper is an original work from the authors. This study is a self-reliance program and did not receive funding from any other sources. This manuscript has not been published and is not currently being considered for publication elsewhere.

The authors grants the journal permission to publish the manuscript.

\section{Competing interests}

The authors declare that they have no competing interests.

\section{Appendix}

Which year are you in the nursing program?

Do you feel any anxiety in your test?

What are the causes for your test anxiety?

Does the program utilize any test accommodation to help you conquer the anxiety?

Can you please define what the accommodations are?

Do you think these accommodations are helpful?

Is there any further suggestion to resolve the issue of test anxiety?

Received: 30 August 2016 Accepted: 20 February 2017

Published online: 02 March 2017

\section{References}

Beggs C, Shields D, Janiszewski-Goodin H (2011) Using guided reflection to reduce test anxiety in nursing students. J Holist Nurs 29:140-147. doi:10.1177/0898010110393352

Bolt SE, Decker DM, Lloyd M, Morlock L (2011) Students' perceptions of accommodations in high school and college. Career Dev Except Individ 34(3):165-175. doi:10.1177/0885728811415098 
Butler S (1996) Child protection or professional self-preservation by the baby nurses? Public health nurses and child protection in Ireland. Soc Sci Med 43:303-314. doi:10.1016/0277-9536(95)00378-9

Cassady JC, Johnson RE (2001) Cognitive test anxiety and academic performance. Contemp Educ Psychol 27(2):270-295. doi:10.1006/ceps.2001.1094

Creswell JW (2013) Qualitative inquiry and research design: choosing among five approaches. Sage, Thousand Oaks

Driscoll R, Evans G, Ramsey G, Wheeler S (2009) High test anxiety among nursing students. Online Submission. Retrieved from http://files.eric.ed.gov/fulltext/ ED506526.pdf

Duggleby W (2005) What about focus group interaction data? Qual Health Res 15:832-840

Edelman M, Ficorelli C (2005) A measure of success: nursing students and test anxiety. J Nurs Staff Dev 21 (2):55-59. doi:10.1097/00124645-200503000-00004

Elliott SN, Marquart AM (2004) Extended time as a testing accommodation: its effects and perceived consequences. Except Child 70:349-367. doi:10.1177/001440290407000306

Enright M, Baldo TD, Wykes SD (2000) The efficacy of eye movement desensitization and reprocessing therapy technique in the treatment of test anxiety of college students. J Coll Couns 3(1):36-48. doi:10.1002/j.2161-1882.2000.tb00162.x

Ergene T (2003) Effective interventions on test anxiety reduction a meta-analysis. Sch Psychol Int 24(3):313-328. doi:10.1177/01430343030243004

Jones S, Torres V, Arminio JL (2014) Negotiating the complexities of qualitative research in higher education: fundamental elements and issues, 2nd edn. Taylor \& Francis, New York

Kafle E (2015) Nursing students with learning disabilities: perceptions and attitude regarding the role of disability support program services and access to accommodations. (Doctoral Dissertation). Capella University

Kennedy DV, Doepke KJ (1999) Multicomponent treatment of a test anxious college student. Educ Treat Child 22:203-217

Krueger RA, Casey MA (2000) Focus groups: a practical guide for applied researchers, 3rd edn. Sage, Thousand Oaks

Kurth N, Mellard D (2006) Student perceptions of the accommodation process in postsecondary education. J Postsecond Educ Disabil 19(1):71-84

Lee K, Osborne R, Carpenter D (2010) Testing accommodations for university students with AD/HD: computerized vs. paper-pencil/regular vs. extended time. J Educ Comput Res. doi:10.2190/EC.42.4.e

Lewandowski L, Lambert TL, Lovett BJ, Panahon CJ, Sytsma MR (2014) College students' preferences for test accommodations. Can J Sch Psychol 29(2):116-126. doi:10.1177/0829573514522116

Lovett BJ (2011) On the diagnosis of learning disabilities in gifted students: Reply to assouline et al. (2010). Gifted Child Quarterly 55(2):149-151. doi:10.1177/0016986210396435

Lovett BJ, Leja AM (2013) Students' perceptions of testing accommodations: what we know, what we need to know, and why it matters. J Appl Sch Psychol 29:72-89. doi:10.1080/15377903.2013.7511477

Mealey DL, Host TR (1992) Coping with test anxiety. Coll Teach 40(4):147-150. doi:10.1080/87567555.1992.10532238

Morgan DL (1988) Focus groups as qualitative research. Sage, Newbury Park

Moustakes C (1994) Phenomenological research methods. Sage, Thousand Oaks

National Center for Education Statistics (2015) Undergraduate Enrollment. U.S. Department of Education. Retrieved from: http://libguides.gwumc.edu/c.php?g=27779\&p=170369

Patton MQ (2002) Qualitative research and evaluation methods, 3rd edn. Sage, Thousand Oaks

Rickey KM (2005) Assessment accommodations for students with disabilities: a description of the decision-making process, perspectives of those affected, and current practices. (Doctoral dissertation). lowa City, University of lowa

Sapp M (1996) Three treatments for reducing the worry and emotionality components of test anxiety with undergraduate and graduate college students: cognitive-behavioral hypnosis, relaxation therapy, and supportive counseling. J Coll Stud Dev 37(1):79-87

Serok S (1991) The application of gestalt methods for the reduction of test anxiety in students. Assess Eval High Educ. 16(2):157-164. doi:10.1080/0260293910160205

Serrantino J, Meeks LM, Jain NR, Clifford GC, Brown JT (2015) Accommodations in didactic, lab, and clinical settings. In: Meeks LM, Jain NR (eds) The guide to assisting students with disabilities: equal access in health science and professional education. Springer, New York, pp 59-87

Shapiro A (2014) Test anxiety among nursing students: a systematic review. Teach Learn Nurs 9:193-202. doi:10.1016/j. teln.2014.06.001

Vorauer JD, Miller DT (1997) Failure to recognize the effect of implicit social influence on the presentation of self. J Pers Soc Psychol 73(2):281. doi:10.1037/0022-3514.73.2.281

\section{Submit your manuscript to a SpringerOpen ${ }^{\circ}$ journal and benefit from:}

- Convenient online submission

- Rigorous peer review

- Immediate publication on acceptance

- Open access: articles freely available online

- High visibility within the field

- Retaining the copyright to your article

Submit your next manuscript at $>$ springeropen.com 